OPEN ACCESS

Edited by: Ali Derakhshan, Golestan University, Iran

Reviewed by: Yadi Sun,

Zhongnan University of Economics and Law, China Reza Bagheri Nevisi, University of Qom, Iran

*Correspondence:

Yuxia Ma

mayuxia2006@163.com

Specialty section:

This article was submitted to Educational Psychology, a section of the journal

Frontiers in Psychology

Received: 04 December 2021 Accepted: 21 December 2021

Published: 15 February 2022

Citation:

Ma Y (2022) On the Relationship

Between English as a Foreign

Language Learners' Positive Affectivity, Academic Disengagement, and Communication Apprehension. Front. Psychol. 12:828873. doi: 10.3389/fpsyg.2021.828873

\section{On the Relationship Between English as a Foreign Language Learners' Positive Affectivity, Academic Disengagement, and Communication Apprehension}

\author{
Yuxia Ma* \\ English Department, School of Foreign Languages and Cultures, Chengdu University, Chengdu, China
}

This review tends to investigate the related studies on the relationships among positive affectivity as a type of positive psychology construct and academic disengagement and communication apprehension (CA) as two types of negative emotions. The negative correlations among CA, disengagement, and positive affectivity like enjoyment have been verified in the review of the literature. Moreover, little research has been done on the relationship between academic disengagement and CA. The studies showed that some factors such as encouraging teaching methodologies, positive classroom context, exciting and challenging classroom tasks can act as mediators in the relationship between positive affectivity and CA. In the end, the pedagogical implications are explicated to foster the language learning quality and to develop a language educational system. Suggestions for further research are provided to develop the existent literature on the relationship between English as a foreign language (EFL) learners' academic disengagement, $\mathrm{CA}$, and their positive affectivity.

\footnotetext{
Keywords: positive psychology, academic disengagement, communication apprehension, positive affectivity, positive classroom context
}

\section{INTRODUCTION}

Positive psychology has drawn the attention of many investigators in foreign language learning since it tries to enhance learning outcomes and foster learning contexts (Han, 2021; Wang et al., 2021). The development of positive psychology owes to Seligman's (2011) theorization of "wellbeing." He developed five-dimensional PERMA including "positive emotion (P), engagement (E), relationships (R), meaning (M), and accomplishment (A)" (p. 12). The enhancement of all five dimensions is the objective of positive psychologists (Wang et al., 2021). On the other hand, the processes of learning a foreign language can be a demanding experience for some learners, and learners' individual differences have been studied in terms of socio-demographic and affective factors such as self-efficacy, apprehension, personality, motivation, and self-efficacy (Kim et al., 2015). More studies need to be done on this issue. This review aims to scrutinize the relationships among apprehension, positive emotions, and engagement in English as a foreign language (EFL) contexts. 


\section{LITERATURE REVIEW}

\section{Apprehension}

Gardner and MacIntyre (1993) pointed out that "Anxiety is fear or apprehension occurring when a learner is expected to perform in the second or foreign language" (p. 59). They linked it to the stimulation of the autonomic nervous system. In a foreign language learning context, Horwitz et al. (1986) coined the term "foreign language anxiety" (FLA) and defined it as "a distinct complex of self-perceptions, beliefs, feelings, and behavior related to classroom language learning arising from the uniqueness of the language-learning process" (p. 28). FLA has been widely considered as a leading factor in academic achievement and language proficiency (MacIntyre, 2017). Studies have testified that higher levels of anxiety are negatively correlated with foreign language proficiency, and with positive orientation and peer emotional support (Zheng and Cheng, 2018). Horwitz (2017) also found out that FLA has a negative significant correlation with some affective factors such as learners' motivation, willingness to communicate, and their self-esteem. Horwitz et al. (1986) categorized FLA construct into Test Anxiety, Fear of Negative Evaluation, and communication apprehension (CA). CA, defined as the avoidance of communications with others (Bourhis and Allen, 1992), has been still widely studied in recent years in communication research (Sham and Azmi, 2018). CA, as a focal point of this review, has a significant correlation with language learners' linguistic background and their proficiency levels (Molnar and Crnjak, 2018). Spetz (2018) investigated Swedish foreign language learners' CA and he attributed it to the level of proficiency in language learners as beginners have a higher level of CA.

\section{Academic Disengagement}

Learners' academic disengagement is one of the most important problems in academic contexts (Lin, 2017). Skinner et al. (2009) defined disengagement as "the absence of engagement including the absence of effort or persistence" (p. 495). Academic engagement is described as "learners' psychological effort and investment toward learning, understanding, or mastering the skills, crafts, or knowledge that the coursework is intended to promote" (Lamborn et al., 1992, p. 13). Learners' academic engagement includes individual and contextual features that interact with each other to demonstrate their positive attitudes toward learning (Zhao et al., 2021). Eccles (2016) argued that learner academic engagement has a positive and significant relationship with academic achievement and resilience. Dörnyei and Ushioda (2011) considered learner motivation a precondition for learner engagement and academic achievement. Gurian et al. (2011), in their study, found out that gender is correlated with differences in learners' academic engagement as males' and females' brain structures differ. Morisse (2015) revealed that females are more academically engaged than males. Rabourn et al. (2015) highlighted the influence of age on learner engagement, and they asserted that adult learners (over 21) have higher academic engagement levels than younger ones. Hashim et al. (2014) also demonstrated that the interaction and rapport between teacher and learner influence learners' engagement. Guilloteaux (2016) asserted that learners' engagement is affected by their background level, task type and difficulty, instructors' methodology and their motivation, and their teaching style. Hung (2015) argued that memorization and rote learning, as two outdated teaching approaches, significantly predict learners' disengagement. He suggested flipped instruction for solving disengagement. Gunuc (2014) also maintained that learner disengagement leads to indifference and frustration, which restrain academic performance.

\section{Positive Affectivity}

According to Agudo (2018), emotions are "subjective, evaluative judgments through which we attempt to interpret the situations we find ourselves in" (p. 386). Traditionally, most investigations have highlighted negative emotions, particularly anxiety. However, with the advent of positive psychology in foreign language studies, most investigators tend to study the facilitative influence of positive affectivity or emotion in foreign language teaching (White, 2018). Pekrun (2014) found out that positive affectivity is significantly related to the learning tasks, intrinsic motivation, the use of language learning strategies, and achievements. Schunk and Greene's (2018) study revealed that the interaction between positive affectivity and self-regulation may result in achievement in language learning, their well-being, and their happiness. Pekrun (2014) has introduced four types of positive emotions that arise during learning activity or outcome: enjoyment, hope, pride, and relief. Goetz et al. (2007) studied the relationship between positive affectivity factors including enjoyment and pride, and negative ones including anger and boredom in various domains, such as English, German, mathematics, and physics classrooms. Their study revealed the context-based differences in the relationships between positive and negative affectivity. They also found stronger relationships between positive and negative emotions in similar subject domains.

\section{The Relationship Between Positive Affectivity and Apprehension}

The relationship between positive affectivity and CA in international educational contexts has been widely studied (Dewaele and MacIntyre, 2014). Enjoyment as one type of positive affectivity has drawn the attention of many investigators since the publication of Dewaele and MacIntyre's (2014) study. Other types of positive affectivity such as pride and hope are not widely studied which can pave the way for future studies. Boudreau et al. (2018) reported enjoyment as one of the most regular phenomena experienced in individuals' life. They defined enjoyment in a foreign language context as a "complex and stable emotion that is completely separate from the more superficial experience of pleasure" (p. 153). Dewaele (2017) mentioned that enjoyment and anxiety have been theorized as two distinct but related aspects in foreign language contexts. They are negatively correlated with each other. The reason for the negative correlation is teachers' approach in increasing foreign language enjoyment and decreasing foreign language apprehension. They 
can provide positive emotional EFL contexts to increase foreign language enjoyment and decrease apprehension levels.

Dewaele and MacIntyre (2014) found a significant negative correlation between enjoyment and CA. Their study also revealed that enjoyment and apprehension or anxiety are not two conflicting constructs. However, a learner may not enjoy in the foreign language context but still have no level of CA (Dewaele and MacIntyre, 2014). Moreover, Dewaele et al. (2018) asserted that learners with significantly high levels of enjoyment and low levels of CA in foreign language contexts had higher levels of language proficiency. Li et al. (2020) also pinpointed the significance of enjoyment and apprehension as the predictors of EFL proficiency at different achievement levels. They attributed this result to the reason that learners with a low level of foreign language apprehension and a high level of enjoyment tend to be more confident and more optimistic which results in higher performance in foreign language proficiency.

Resnik and Dewaele (2020) also studied enjoyment and CA among the first language (German participants) and foreign language learners (English participants). Their study revealed that, in a foreign language context, higher levels of apprehension and enjoyment were observed. Furthermore, there was a negative correlation between enjoyment and apprehension in first and foreign language contexts. They attributed their results to the use of educational approaches in foreign language classrooms may lead to higher levels of apprehension and enjoyment. Pavelescu and Petrić (2018) provided some factors such as peer interaction, supportive and encouraging teaching, positive classroom context, exciting and challenging classroom tasks which play as mediator variables between apprehension and enjoyment in EFL contexts. These variables should be scrutinized in more detail to clarify the relationship between enjoyment and apprehension in foreign language contexts.

Pride, as another aspect of positive affectivity, has received little attention (Artino and Jones, 2012). Heckel and Ringeisen (2019) investigated pride and apprehension and learners' selfefficacy, interest, and satisfaction in online learning contexts. Their study showed a negative significant relationship between self-efficacy and apprehension and a positive significant relationship between pride and self-efficacy, interest and satisfaction. They found a negative relationship between pride and anxiety and they attributed this result to the fact that pride depends on dispositional control along with contextual value appraisals, while apprehension is mainly related to dispositional control appraisals.

\section{The Relationship Between Engagement, Disengagement, and Positive Affectivity}

Most studies have been done on the influence of learners' and instructors' individual differences and their relations with learners' engagement in foreign language contexts and their linguistic proficiency (Xie and Derakhshan, 2021). A significant correlation between learner engagement and teacher-student rapport and non-verbal immediacy, as two elements of positive psychology, has been identified (Derakhshan, 2021; Greenier et al., 2021). However, the related studies ratified the implication of promoting engagement in foreign language learning contexts since it triggers two components of positive psychology like learners' motivation and enjoyment and results in learners' academic achievement (Dewaele and Li, 2020; Zeng, 2021). Mercer and Dörnyei (2020) argued that foreign language learners' enjoyment positively correlates with their engagement in language learning contexts. They also maintained that learners' enjoyment of foreign languages can support their academic engagement. Learners are enthusiastically, interactively, and cognitively involved in language learning than genetically. They ascribed their results to the custom of venerating the teacher and valuing his teaching in the educational context.

Jin and Zhang (2019) asserted that language learning enjoyment can lead to engagement in learning contexts and it can improve social-behavioral learning engagement. They emphasized that enjoyment may lead to constant willpower along with engagement in instructive contexts. Liu (2021) investigated the way of developing learners' positive affectivity by increasing their engagement. He indicated that learner enjoyment, arising from peer relations, teacher-instructor rapport and the difficulty of the tasks is a significant element to support learner engagement. Philp and Duchesne (2016) regarded engagement as a determining factor for motivation and they argued that engagement is an apparent indicator of cognitive and emotional behavior in the form of enjoyment and it influence effort and strategies for learning.

Regarding disengagement, Chipchase et al. (2017) identified attendance, preparation for class, time and effort spent studying, collaborative study, assessment, academic performance, and enjoyment as the indicators of academic disengagement. Most of these indices are behavior and cognitive reasons for disengagement and only lack of enjoyment is the psychological reason for disengagement. These variables can offer a basis for the preparation of a screening tool to gauge learner disengagement. These variables should be considered in more detail in future studies and the reasons for academic disengagement should be meticulously studied. Overall, positive affectivity is related to intensified engagement, whereas negative affectivity is associated with academic disengagement. Particularly, enjoyment promotes engagement (Ainley and Ainley, 2011).

\section{The Relationship Between Engagement, Disengagement, and Apprehension}

According to Dörnyei and Ushioda (2011), learning a foreign language includes interaction between motivation, cognition, and affection. Since individual differences are characterized by "highly interrelated, multifaceted, complicated, and dynamic" (Butler, 2019, p. 4), it can be mentioned that CA or anxiety and academic engagement have direct and indirect relationships with each other (Zhang et al., 2020). Few studies have been done on the effect of engagement on anxiety. Kashdan and Fincham (2004), in their study, found out that anxiety and disengagement happen when academic problems are observed. Zhang et al. (2020) in their study, found out that L2 motivators outperform L2 demotivators in predicting learners' engagement in EFL contexts and their CA. Generally, they pointed out 
that the consideration of methodologies used in classroom and testing approaches can support L2 motivation and learners' academic engagement. They maintained that engagement acts as a mediator role in L2 de/motivation, whereas, CA may hold back learners' academic achievement and improve their intention to engage in the EFL classrooms. Li (2021) also argued apprehension can bring about that permanent harm in learners' performance since anxious learners may not have many chances to express themselves and to engage themselves in language learning contexts.

\section{DISCUSSION}

This review tried to investigate the related literature reviews on apprehension and disengagement as negative emotions. However, positive affectivity, especially enjoyment, has been meticulously studied. This review scrutinized the studies related to the negative relationship between enjoyment and apprehension. However, some factors such as learners' confidence, negative and positive attitudes and teachers' educational methodologies can as mediator variables between learners' classroom enjoyment and their apprehension. This review also highlighted the studies which prove the significant relationship between enjoyment and engagement in foreign language contexts. We can attribute this positive correlation to peer relations, teacher-instructor rapport, and challenging tasks as they increase learners' feeling of enjoyment, competitiveness, and academic engagement. Few studies also considered a negative relationship between apprehension and engagement. In other words, the more anxious a learner feels, the less engaged they are to probably join in class activities. More studies are required to consider this correlation in more detail both among learners and teachers.

\section{Implications and Suggestions}

This review investigated the correlations between learners' communicative apprehension, engagement, and positive affectivity. Considering the related studies on the relationship among affective factors, it can be mentioned that learners should be assisted to control, adjust, and regulate their feelings in language learning contexts. Lack of regulating or controlling affections may diminish the enjoyment of learners which may trigger teacher educators to consider this issue in practical aspects (Schutz and Zembylas, 2009). The review of literature can motivate instructors, school principals, and policymakers to ponder into EFL learners' behaviors, characteristics, and their positive effects. The literature implied that positive affectivity such as enjoyment and pride and negative emotions such as academic disengagement and apprehension or anxiety occur in L2 classes.

This review implies that instructors can modify learners' academic enjoyment, engagement and lessen their apprehension by providing a peaceful context for language learning. Therefore, L2 instructors require courses to enhance learners' attitudes and motivation for increasing their positive affectivity such as foreign language enjoyment, engagement, pride, etc., and to alleviate negative feelings such as $\mathrm{CA}$, disengagement, etc. in their classes. Furthermore, the knowledge of EFL learners' characters may inspire instructors to be more stable and engaging in their behavior in language contexts. They can provide learners with chances for foreign language enjoyment, and they are required to diminish learners' CA, disengagement, tension and improve resilience despite educational problems in language learning contexts to enhance L2 learning experiences. They can provide foreign language input by boosting studentstudent interactions. In a foreign language context, learners' $\mathrm{CA}$ is related to their language proficiency level and their linguistic background (Molnar and Crnjak, 2018), therefore homogenizing the classroom can be an appropriate approach to deal with this problem. Furthermore, instructive supervisors who monitor instructors and assess their academic efficiency can exploit the related studies through consideration of the instructors' interpersonal behaviors and their rapport with the learners. Policymakers can develop engagement programs that help learners decrease their CA and amplify their academic engagement. They can positively support learners and make a context in which learners can take part in positive behaviors.

The schools and institutes' managers should provide EFL contexts in support of learners' engagement and enjoyment by offering to authenticate, joyful and updated materials to teachers and learners. They can recommend teachers to use interesting teaching methodology and styles which arouse learners' excitement and enjoyment to engage in the classroom. Given that the learners' academic engagement is a primary facet of education, the anticipation of strategies for intensifying learners' enjoyment and engagement in pre-service and in-service teacher training programs by teacher educators can be valuable. Also, it is recommended that school managers hold instructive workshops bearing in mind learners' apprehension, their enjoymentt, and academic engagement. Lastly, the importance of academic engagement and enjoyment makes advisors widen agendas to upsurge the influence of these academic engagements and enjoyment on learning achievement. They can identify learners' sources of academic disengagement.

This review has raised numerous questions for further investigations. Future studies may consist of investigating the influence of other individual variables including learner's extroversion, introversion, and many others. The causes of positive affectivity and CA should be investigated to reveal the primary causes for classroom emotions. Moreover, reciprocity of the relationship between foreign language affectivity and apprehension should be studied in the future. Other studies can be done to investigate which linguistic tasks can alleviate learners' apprehension and their academic disengagements. Longitudinal studies are required to shed light on the intrapersonal and interpersonal emotions in language learning. Dörnyei and Ryan (2015) also suggested the requirement of longitudinal and dynamic research approaches that show learners' changing nature in emotions in language learning contexts. Future studies can investigate the effects of positive psychology constructs on the 
working memory of EFL learners. Moreover, the effects of positive psychology constructs on the improvement of language skills should be studied in detail. Language learning via online language teaching has been disturbed severely during the COVID-19 pandemic in the EFL context (Wang and Derakhshan, 2021). Further studies are needed to determine learners' academic engagement, $\mathrm{CA}$, and their positive affectivity in traditional and digital contexts to illuminate how these contexts may affect learners' emotions (Wang and Guan, 2020). Furthermore, further research can be done to investigate the gender effect on the positive and negative emotions experienced in language learning contexts. Finally, future studies should pinpoint the relationship between EFL learners' emotional intelligence and their disengagement in foreign language contexts.

\section{REFERENCES}

Agudo, M. J. (2018). Emotions In Second Language Teaching: Theory, Research And Teacher Education. Cham: Springer.

Ainley, M., and Ainley, J. (2011). Student engagement with science in early adolescence: the contribution of enjoyment to students' continuing interest in learning about science. Contemp. Educ. Psychol. 36, 4-12.

Artino, A. R., and Jones, K. D. (2012). Exploring the complex relations between achievement emotions and self-regulated learning behaviors in online learning. Internet High. Educ. 15, 170-175. doi: 10.1016/j.iheduc.2012.01.006

Boudreau, C., MacIntyre, P. D., and Dewaele, J. M. (2018). Enjoyment and anxiety in second language communication: an idiodynamic approach. Stud. Second Lang. Learn. Teach. 8, 149-170. doi: 10.14746/ssllt.2018.8.1.7

Bourhis, J., and Allen, M. (1992). Meta-analysis of the relationship between communication apprehension and cognitive performance. Commun. Educ. 41, 68-76.

Butler, Y. G. (2019). Linking noncognitive factors back to second language learning: new theoretical directions. System 86:102127

Chipchase, L., Davidson, M., Blackstock, F., Bye, R., Clothier, P., Klupp, N., et al. (2017). Conceptualizing and measuring student disengagement in higher education: a synthesis of the literature. Int. J. High. Educ. 6, 31-42. doi: 10.5430/ ijhe.v6n2p31

Derakhshan, A. (2021). The predictability of Turkman students' academic engagement through Persian language teachers' nonverbal immediacy and credibility. J. Teach. Persian Speakers Other Lang. 10, 3-26. doi: 10.30479/ JTPSOL.2021.14654.1506

Dewaele, J. M. (2017). "Psychological dimensions and foreign language anxiety," in The Routledge Handbook Of Instructed Second Language Acquisition, eds S. Loewen and M. Sato (London: Routledge), 433-450.

Dewaele, J. M., and Li, C. (2020). Emotions in second language acquisition: a critical review and research agenda. Foreign Lang. World 1, 34-49.

Dewaele, J.-M., and MacIntyre, P. D. (2014). The two faces of Janus? Anxiety and enjoyment in the foreign language classroom. Stud. Second Lang. Learn. Teach. 4, 237-274. doi: 10.14746/ssllt.2014.4.2.5

Dewaele, J. M., Witney, J., Saito, K., and Dewaele, L. (2018). Foreign language enjoyment and anxiety in the FL classroom: the effect of teacher and learner variables. Lang. Teach. Res. 22, 676-697. doi: 10.1177/1362168817692161

Dörnyei, Z., and Ryan, S. (2015). The Psychology Of The Language Learner: Individual Differences In Second Language Acquisition: Revisited. New York: Routledge.

Dörnyei, Z., and Ushioda, E. (2011). Teaching And Researching Motivation. Harlow: Pearson Education.

Eccles, J. (2016). Engagement: where to next? Learn. Instruct. 43, 71-75. doi: 10.1016/j.learninstruc.2016.02.003

Gardner, R. C., and MacIntyre, P. D. (1993). On the measurement of affective variables in second language learning. Lang. Learn. 43, 157-194. doi: 10.1111/j. 1467-1770.1992.tb00714.x

\section{AUTHOR CONTRIBUTIONS}

YM the sole author confirms the final manuscript and approved its submission to Frontiers in Psychology.

\section{FUNDING}

This study was sponsored by the Chengdu University Fund Project "A study of Interpersonal Impoliteness from the Perspective of Identity Construction Theory" (Grant No. 2018XSB06) and Sichuan Social Planning Project "Research on Relational Work in Multimodal Networked Interaction" (Grant No. SC19WY001).

Goetz, T., Frenzel, A., Pekrun, R., Hall, N., and Lüdtke, O. (2007). Between- and within-domain relations of students' academic emotions. J. Educ. Psychol. 99, 715-733. doi: 10.1037/0022-0663.99.4.715

Greenier, V., Derakhshan, A., and Fathi, J. (2021). Emotion regulation and psychological well-being in teacher work engagement: a case of British and Iranian English language teachers. System 97:102446.

Guilloteaux, M. J. (2016). Student engagement during EFL high school lessons in Korea. Exp. Samp. Study 23, 21-46. doi: 10.15334/FLE.2016.23.1.21

Gunuc, S. (2014). The relationships between student engagement and their academic achievement. Int. J. N. Trends Educ. 5, 216-231.

Gurian, M., Stevens, K., Henley, P., and Trueman, T. (2011). Boys And Girls Learn Differently! A Guide For Teachers And Parents. San Francisco: Jossey-Bass.

Han, K. (2021). Fostering students' autonomy and engagement in EFL classroom through proximal classroom factors: autonomy-supportive behaviors and student-teacher relationships. Front. Psychol. 12:767079. doi: 10.3389/fpsyg. 2021.767079

Hashim, N. M., Alam, S. S., and Yusoff, N. M. (2014). Relationship between teacher's personality, monitoring, learning environment, and students' EFL performance. GEMA Online J. Lang. Stud. 14, 101-116. doi: 10.17576/GEMA2014-1401-07

Heckel, C., and Ringeisen, T. (2019). Pride and anxiety in online learning environments: achievement emotions as mediators between learners' characteristics and learning outcomes. J. Comput. Assist. Learn. 35, 667-677. doi: $10.1111 /$ jcal.12367

Horwitz, E. K. (2017). “On the misreading of Horwitz, Horwitz, and Cope (1986) and the need to balance anxiety research and the experiences of anxious language learners," in New Insights Into Language Anxiety: Theory, Research And Educational Implications, eds C. Gkonou, M. Daubney, and J.-M. Dewaele (Bristol: Multilingual Matters), 31-47.

Horwitz, E. K., Horwitz, M. B., and Cope, J. (1986). Foreign language classroom anxiety. Modern Lang. J. 70, 125-132. doi: 10.2307/327317

Hung, H. (2015). Flipping the classroom for English language learners to foster active learning. Comput. Assist. Lang. Learn. 28, 81-96. doi: 10.1080/09588221. 2014.967701

Jin, Y., and Zhang, L. J. (2019). A comparative study of two scales for foreign language classroom enjoyment. Percept. Motor Skills 126, 1024-1041. doi: 10. $1177 / 0031512519864471$

Kashdan, T. B., and Fincham, F. D. (2004). "Facilitating curiosity: a social and self-regulatory perspective for scientifically based interventions," in Positive Psychology In Practice, eds P. A. Linley and S. Joseph (Hoboken: Wiley), 482-503.

Kim, D. H., Wang, C., Ahn, H., and Bong, M. (2015). English language learners' self-efficacy profiles and relationship with self-regulated learning strategies. Learn. Individ. Differ. 38, 136-142. doi: 10.1016/j.lindif.2015.01.016

Lamborn, S., Newmann, F., and Wehlage, G. (1992). “The significance and sources of student engagement," in Student Engagement And Achievement In American Secondary Schools, ed. F. Newmann (New York: Teachers College Press), 11-39. 
Li, C., Dewaele, J. M., and Jiang, G. (2020). The complex relationship between classroom emotions and EFL achievement in China. Appl. Linguist. Rev. 11, 485-510. doi: 10.1515/applirev-2018-0043

Li, X. (2021). EFL teachers' apprehension and L2 students' classroom engagement. Front. Psychol. 12:758629. doi: 10.3389/fpsyg.2021.758629

Lin, L. F. (2017). Impacts of the problem-based learning pedagogy on English learners' reading comprehension, strategy use, and active learning attitudes. J. Educ. Train. Stud. 5, 109-125. doi: 10.11114/jets.v5i6.2320

Liu, H. (2021). Engaging language learners in contemporary classrooms. ELT J. 75, 232-234. doi: 10.1093/elt/ccab004

MacIntyre, P. D. (2017). "An overview of language anxiety research and trends in its development," in New Insights Into Language Anxiety: Theory, Research And Educational Implications, eds C. Gkonou, M. Daubney, and J.-M. Dewaele (Bristol: Multilingual), 11-30.

Mercer, S., and Dörnyei, Z. (2020). Engaging Language Learners In Contemporary Classrooms. Cambridge: Cambridge University Press.

Molnar, D., and Crnjak, G. (2018). Exploring foreign language communication apprehension among the English language university students in the English language classroom setting. Eur. J. Soc. Sci. Educ. Res. 5, 110-130. doi: 10.26417/ ejser.v5i2.p27-39

Morisse, K. (2015). "Inverted classroom: from experimental usage to curricular anchorage," in Proceedings of the 10th European Conference on E-learning, Vol. 10 (Nassau: College of the Bahamas), 218-226.

Pavelescu, L. M., and Petrić, B. (2018). Love and enjoyment in context: four case studies of adolescent EFL learners. Stud. Second Lang. Learn. Teach. 8, 73-101. doi: 10.14746/ssllt.2018.8.1.4

Pekrun, R. (2014). Emotions And Learning. Genova: UNESCO International Bureau of Education.

Philp, J., and Duchesne, S. (2016). Exploring engagement in tasks in the language classroom. Ann. Rev. Appl. Linguist. 36, 50-72. doi: 10.1017/ S0267190515000094

Rabourn, K. E., Shoup, R., and BrckaLorenz, A. (2015). "Barriers in returning to learning: engagement and support of adult learners," in Paper Presented at the Annual Forum of the Association for Institutional Research, Denver.

Resnik, P., and Dewaele, J.-M. (2020). Trait emotional intelligence, anxiety and enjoyment in first and foreign language classes. System 94:102324. doi: 10.1016/ j.system.2020.102324

Schunk, D., and Greene, J. (2018). Handbook Of Self-Regulation Of Learning And Performance. New York: Routledge.

Schutz, P. A., and Zembylas, M. (2009). "Introduction to advances in teacher emotion research: the impact on teachers' lives," in Advances in Teacher Emotion Research, eds P. Schutz and M. Zembylas (Boston, MA: Springer), 3-11. doi: 10.1007/978-1-4419-0564-2_1

Seligman, M. E. P. (2011). Learned Optimism: How to Change your Mind and Your Life. New York, NY: Vintage. doi: 10.1136/bmj.316.7134.870

Skinner, E. A., Kindermann, T. A., and Furrer, C. J. (2009). A motivational perspective on engagement and disaffection: conceptualization and assessment of children's behavioral and emotional participation in academic activities in the classroom. Educ. Psychol. Meas. 69, 493-525. doi: 10.1177/0013164408323233
Sham, R., and Azmi, M. (2018). Causal relationship between oral performance and communication apprehension. KnE Soc. Sci. 3:769. doi: 10.18502/kss.v3i4.1984

Spetz, H. (2018). L'anxiété Langagière et la Production Orale Une Étude sur les Étudiants Suédois de Français Langue Étrangère à L'université. Available online at: http://www.divaportal.org/smash/get/diva2:1222877/FULLTEXT01.pdf

Wang, Y. L., and Derakhshan, A. (2021). [Review of the book Professional development of CLIL teachers, by Y. Y. Lo]. Int. J. Appl. Linguist. 1-4. doi: 10.1111/ijal.12353

Wang, Y. L., Derakhshan, A., and Zhang, L. J. (2021). Researching and practicing positive psychology in second/foreign language learning and teaching: the past, current status and future directions. Front. Psychol. 12:731721. doi: 10.3389/ fpsyg.2021.731721

Wang, Y. L., and Guan, H. F. (2020). Exploring demotivation factors of Chinese learners of English as a foreign language based on positive psychology. Rev. Argent. Clin. Psicol. 29, 851-861. doi: 10.24205/03276716.2020.116

White, C. J. (2018). "The emotional turn in applied linguistics and TESOL: significance, challenges and prospects," in Emotions In Second Language Teaching, ed. J. Martínez Agudo (Berlin: Springer), 125-141.

Xie, F., and Derakhshan, A. (2021). A conceptual review of positive teacher interpersonal communication behaviors in the instructional context. Front. Psychol. 12:708490. doi: 10.3389/fpsyg.2021.708490

Zeng, Y. (2021). A review of foreign language enjoyment and engagement. Front. Psychol. 12:737613. doi: 10.3389/fpsyg.2021.737613

Zhang, X., Dai, S., and Ardasheva, Y. (2020). Contributions of (de)motivation, engagement, and anxiety to English listening and speaking. Learn. Individ. Differ. 79:101856. doi: 10.1016/j.lindif.2020.101856

Zhao, H., Xiong, J., Zhang, Z., and Qi, C. (2021). Growth mindset and college students' learning engagement during the COVID-19 pandemic: a serial mediation model. Front. Psychol. 12:621094. doi: 10.3389/fpsyg.2021.621094

Zheng, Y., and Cheng, L. (2018). How does anxiety influence language performance? From the perspectives of foreign language classroom anxiety and cognitive test anxiety. Lang. Test. Asia 8:13. doi: 10.1186/s40468-018-0065-4

Conflict of Interest: The author declares that the research was conducted in the absence of any commercial or financial relationships that could be construed as a potential conflict of interest.

Publisher's Note: All claims expressed in this article are solely those of the authors and do not necessarily represent those of their affiliated organizations, or those of the publisher, the editors and the reviewers. Any product that may be evaluated in this article, or claim that may be made by its manufacturer, is not guaranteed or endorsed by the publisher.

Copyright (c) $2022 \mathrm{Ma}$. This is an open-access article distributed under the terms of the Creative Commons Attribution License (CC BY). The use, distribution or reproduction in other forums is permitted, provided the original author(s) and the copyright owner(s) are credited and that the original publication in this journal is cited, in accordance with accepted academic practice. No use, distribution or reproduction is permitted which does not comply with these terms. 